\title{
Size- and charge-dependent non-specific uptake of PEGylated nanoparticles by macrophages
}

This article was published in the following Dove Press journal:

International Journal of Nanomedicine

14 February 2012

Number of times this article has been viewed

\author{
Shann SYu ${ }^{1,2}$ \\ Cheryl M Lau' \\ Susan N Thomas ${ }^{3}$ \\ W Gray Jerome ${ }^{4}$ \\ David J Maron ${ }^{5}$ \\ James H Dickerson ${ }^{2,6}$ \\ Jeffrey A Hubbell ${ }^{3}$ \\ Todd D Giorgio 1,2,7,8
}

'Department of Biomedical Engineering, Vanderbilt University, Nashville, ${ }^{2}$ Vanderbilt Institute of Nanoscale Science and Engineering, Nashville, TN, USA; ${ }^{3}$ nstitute of Bioengineering, École Polytechnique Fédérale de Lausanne, Lausanne, Switzerland, ${ }^{4}$ Department of Pathology, Vanderbilt University Medical Center, Nashville, ${ }^{5}$ Vanderbilt Heart and Vascular Institute, Nashville, ${ }^{6}$ Department of Physics and Astronomy, Vanderbilt University, Nashville, ${ }^{7}$ Department of Cancer Biology, Vanderbilt University Medical Center, Nashville, ${ }^{8}$ Department of Chemical and Biomolecular Engineering, Vanderbilt University, Nashville, TN, USA
Correspondence: Todd D Giorgio Vanderbilt University, VU Station B, Box 35I63I, Nashville, TN 37235, USA

Tel +l 6I5 3431099

Fax + I 6153437919

Email todd.d.giorgio@vanderbilt.edu

\begin{abstract}
The assessment of macrophage response to nanoparticles is a central component in the evaluation of new nanoparticle designs for future in vivo application. This work investigates which feature, nanoparticle size or charge, is more predictive of non-specific uptake of nanoparticles by macrophages. This was investigated by synthesizing a library of polymer-coated iron oxide micelles, spanning a range of $30-100 \mathrm{~nm}$ in diameter and $-23 \mathrm{mV}$ to $+9 \mathrm{mV}$, and measuring internalization into macrophages in vitro. Nanoparticle size and charge both contributed towards non-specific uptake, but within the ranges investigated, size appears to be a more dominant predictor of uptake. Based on these results, a protease-responsive nanoparticle was synthesized, displaying a matrix metalloproteinase-9 (MMP-9)-cleavable polymeric corona. These nanoparticles are able to respond to MMP-9 activity through the shedding of 10-20 nm of hydrodynamic diameter. This MMP-9-triggered decrease in nanoparticle size also led to up to a six-fold decrease in nanoparticle internalization by macrophages and is observable by $T_{2}$-weighted magnetic resonance imaging. These findings guide the design of imaging or therapeutic nanoparticles for in vivo targeting of macrophage activity in pathologic states.
\end{abstract}

Keywords: macrophage targeting, poly(ethylene glycol) (PEG), poly(propylene sulfide) (PPS), iron oxides, opsonization

\section{Introduction}

As one of the most phagocytic cells in the human body, macrophages are among the first cells of the innate immune system to arrive at a site of injury, but also have been observed as permanent residents in certain organs, such as in the liver and bone marrow. ${ }^{1-3}$ They function to clear pathogens and microbes, as well as host cell and matrix debris that are present at sites of tissue injury. Macrophages recognize and interact with this multitude of potential targets through a variety of mechanisms, including phagocytosis and receptor-mediated endocytosis. The latter is mediated primarily through pattern recognition receptors, which include toll-like receptors, the mannose receptor (CD206), and scavenger receptor A (CD204). ${ }^{4-6}$ The polygamous nature of these pattern-recognition receptors is not restricted to natural ligands and targets. For example, CD204 has a wide range of molecular partners, leading to receptor-mediated endocytosis, distinct from the non-specific uptake due to pinocytosis. ${ }^{7}$ For the purposes of this manuscript, we have defined this polygamous behavior as "non-specific" uptake or internalization. This is emphasized by evidence that CD204 has been shown to contribute to the non-specific uptake of nanoparticles surface-functionalized with carboxylic acids, antibodies, as well as synthetic polymers ${ }^{8,9}$ Therefore, the rational design of nanoparticles for in vivo use requires an application-driven minimization 
or optimization of such non-specific interactions between macrophages and synthetic nanoparticles. However, this area remains largely uninvestigated.

Non-specific interactions between macrophage receptors and nanoparticles may be dictated by a variety of characteristics, including particle size, shape, surface charge, and hydrophobicity, and facilitated by surface chemistry-specific complement activation on the nanoparticle. ${ }^{10,11}$ Doshi and Mitragotri treated macrophages at $4^{\circ} \mathrm{C}$ with a library of polystyrene microparticles exhibiting a variety of sizes and shapes to mimic bacterial dimensions, and observed optimal attachment for rod-shaped particles with the longest dimension at $2-3 \mu \mathrm{m} .{ }^{11}$ However, the smallest particles investigated were in the range of $500 \mathrm{~nm}$; work with such nanoparticles has yet to be extended to the sub-100 nm dimensional range, which is of interest in many in vivo applications. Raynal et al showed that macrophages exhibit size-dependent uptake of nanoparticles functionalized with dextran, but macrophages can interact directly with dextran, as their expression of a dextran receptor (SIGNR1) was later documented. ${ }^{12,13}$

Therefore, in this work, we sought to investigate nonspecific uptake of synthetic nanoparticles by macrophages, extending the work of these earlier groups into sub-100 nm PEGylated nanoparticles. To our knowledge, this is the first investigation of the effects of nanoparticle size, surface chemistry, and charge on non-specific uptake by macrophages. The rationale for using a PEG-functionalized nanoparticle system to accomplish these objectives is that macrophages are unlikely to have specific receptors for poly(ethylene glycol) (PEG). Further, PEG can be easily modified to display various chemical functionalities, enabling the modulation of nanoparticle charge without significantly varying the bulk properties of the PEG coating. This is also a relevant model system for study because PEGylation of nanoparticles is commonly performed in order to render synthetic nanoparticles water-soluble and applicable for in vivo use. This is, in part, because PEG has been shown to discourage protein adsorption and opsonization on nanomaterial surfaces. ${ }^{14}$

Therefore, we used block copolymers of poly(ethylene glycol)-bl-poly(propylene sulfide) (PEG-PPS), which are amphiphilic copolymers that are capable of forming micelles and stabilizing hydrophobic drugs and nanoparticles at their liquid, PPS core. ${ }^{15,16}$ The incorporation of ultrasmall superparamagnetic iron oxides (USPIOs) into the micellar core of PEG-PPS block copolymers serves two functional purposes - enabling easy quantification of particle uptake through colorimetric assays, while also being a widely investigated contrast agent for $T_{2}$-weighted magnetic resonance imaging (MRI). Through the use of a variety of materials processing techniques to form the micelles, including thin film hydration and direct hydration, the same starting PEGPPS copolymers and iron oxide cores can lead to monodisperse micelles (PEG-PPS-USPIOs) exhibiting hydrodynamic diameters at $30 \mathrm{~nm}, 40 \mathrm{~nm}$, or $100 \mathrm{~nm}$. Additionally, PEG-PPS-USPIOs can be fashioned with different surface chemistries at the PEG terminus, enabling an examination of charge-dependent non-specific uptake of nanoparticles by the macrophages.

To demonstrate the utility of these studies, we evaluated a protease-activity MRI probe design against these results. To make activity probes, PEG chains containing a proteasecleavable peptide substrate were synthesized and conjugated to PPS, in order to fashion surfactants for the micellization of USPIOs. The resulting nanoparticles are "activatable" by protease activity through a $\geq 10 \mathrm{~nm}$ decrease in hydrodynamic diameter. Macrophages are therefore expected to internalize protease-treated nanoparticles differently than untreated nanoparticles. We hypothesize that these differences can be visualized via MRI with the aid of the contrast agent USPIOs encapsulated within the micelles. Taken together, the work presented here shows methods to design ideal nanoparticle dimensions and properties in order to better optimize nanoparticle behavior in vivo.

\section{Materials and methods}

All reagents were purchased from Sigma-Aldrich (St Louis, MO) and used as purchased unless otherwise noted below. Matrix metalloproteinase-9 (MMP-9), MMP-9 inhibitor, Fmoc-protected L-amino acids, and resins for solid-phase peptide synthesis were purchased from EMD Biosciences (Gibbstown, NJ). PEG reagents were purchased from Laysan Biosciences (Arab, AL). All dialysis supplies were ordered from Pierce Scientific (Rockford, IL) and used with modifications to the factory-provided protocol as indicated in the appropriate sections below. Copper transmission electron microscopy (TEM) grids with Formvar film and uranyl acetate were purchased from Electron Microscopy Sciences (Hatfield, PA). GIBCO ${ }^{\circledR}$ RPMI-1640 medium, penicillinstreptomycin, and fetal bovine serum (FBS) were purchased from Life Technologies (Carlsbad, CA).

\section{PEG-PPS block copolymers and functionalization}

Synthesis of approximately $7 \mathrm{kDa}$ carboxy-PEG-PPS (cPEG-PPS) was carried out as previously described. ${ }^{16}$ For fluorescent polymers, FITC-PEG-NH 2 was used 
in place of $\mathrm{cPEG}-\mathrm{NH}_{2}$ in the coupling reaction to PPS. The MMP-9-cleavable peptide GGPRQITAGC (M9C; GlyGly-Pro-Arg-Gln-Ile-Thr-Ala-Gly-Cys) ${ }^{17}$ was synthesized on a Rink-amide MBHA resin support, via standard Fmocbased solid phase peptide synthesis on an automated system (Protein Technologies PS3, Tucson, AZ).$^{18}$ The peptide (1.5 eq, $45 \mathrm{mmol}$ ) was then reacted overnight with 1 eq of $5 \mathrm{kDa}$ methoxy-PEG-maleimide (mPEG-MAL; $30 \mathrm{mmol}$; $150 \mathrm{mg}$ ), in an aqueous buffer containing $0.1 \mathrm{M} \mathrm{Na}_{3} \mathrm{PO}_{4}$ and $0.15 \mathrm{M} \mathrm{NaCl}$ at $\mathrm{pH}$ 7.2. Unbound peptide was removed by dialysis across a $2 \mathrm{kDa}$ molecular weight cutoff membrane overnight at room temperature. The completed mPEG-[M9C] conjugate was lyophilized, then coupled to cPEG-PPS via standard carbodiimide chemistry to yield mPEG-[M9C]PEG-PPS block copolymers.

For Fourier transform infrared (FT-IR) spectroscopy, polymer samples were prepared by mixing with IR-grade $\mathrm{KBr}$ and pelleting on a $\mathrm{KBr}$ press (Specac, Slough, UK). FT-IR was performed on a Bruker Tensor 27 system (Billerica, MA).

Proton nuclear magnetic resonance (1H NMR) spectra were obtained at $400 \mathrm{MHz}$ using a 9.4 Tesla Oxford magnet operated by a Bruker AV-400 console. The main NMR probe

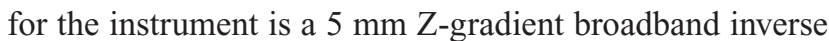
(BBI) probe with automatic tuning and matching capability (ATM)

Gel permeation chromatography (GPC) was performed on three resolving columns running in series $(1 \times$ TSKGel Alpha4000, $2 \times$ TSKGel Alpha3000; Tosoh Bioscience, King of Prussia, PA) with dimethylformamide (DMF) +0.1 $\mathrm{M} \mathrm{LiBr}$ mobile phase. Columns were incubated at $60^{\circ} \mathrm{C}$, and chromatograms were obtained with a Shimadzu SPD-10A UV detector and RID-10A refractive index detector (Shimadzu Scientific Instruments, Columbia, MD), and a Wyatt miniDAWN Treos multi-angle light scattering detector (MALS; Wyatt Technology, Santa Barbara, CA). Data collection and analysis was achieved through the Wyatt ASTRA software (v 5.3.4).

\section{Encapsulation of USPIOs in PEG-PPS copolymers}

Synthesis of hydrophobic, monodisperse USPIO core particles and their encapsulation in PEG-PPS copolymers was carried out as previously described. ${ }^{16}$ In brief, USPIO cores of predictable diameters were first synthesized through thermal decomposition, by controlling the molar ratios of iron precursor to oleic acid introduced in the reaction feed (Supplementary Figure S1). A 1:2 mass ratio of dried hydrophobic USPIO cores to PEG-PPS polymers were then dissolved in toluene, vortexed to mix, sonicated for 5 seconds to break apart clumps, and then dried by rotary evaporation for 20 minutes. The dried polymer/USPIO mixture was then rehydrated in $3 \mathrm{~mL}$ of nanopure water and vortexed vigorously to suspend all particulates. Large clumps and byproducts were removed by magnetic pelleting, and the colloidal phase was collected and further centrifuged at $2500 \mathrm{~g}$ for 5 minutes to precipitate excess polymers. The supernatant is gently aspirated by pipette into fresh scintillation vials and stored at $4^{\circ} \mathrm{C}$.

To fabricate fluorescent micelles, a 1:40:20.5 mass ratio of FITC-PEG-PPS:PEG-PPS: iron oxide cores was mixed and micellized as described above. Therefore, the overall mass ratio of polymers to iron oxides is preserved at 1:2 for all micellization procedures. To make "proximity-activated" USPIOs (PA-USPIOs) - which are able to respond to local MMP-9 activity, OA-USPIOs were encapsulated in MMP9-cleavable mPEG-[M9C]-PEG-PPS polymers using the same protocol.

\section{Pluronic $^{\circledR}$-PPS nanoparticles and loading with USPIOs}

Pluronic-stabilized PPS nanoparticles (NPs) were synthesized by inverse emulsion polymerization as described previously. ${ }^{10,19}$ Pluronic F-127 (a block copolymer of polyethylene glycol and polypropylene glycol terminated by $\alpha$ and $\omega$ hydroxyl groups) was used alone or in combination with carboxyl-terminated Pluronic derivatized as previously described. ${ }^{20}$ The hydrophobic core was stabilized by disulfide crosslinking of the linear PPS chains. ${ }^{19}$ However, since crosslinking cannot reach completion, remaining free sulfhydryl groups on the NP surface were irreversibly capped by reaction with the alkylating reagent iodoacetamide. NP solutions were sterile-filtered, and then loaded with $3 \mathrm{~nm}$ USPIO cores through a direct hydration process. Then $100 \mu \mathrm{L}$ of the hydrophobic OA-USPIOs $(20 \mathrm{mg} / \mathrm{mL}$ in tetrahydrofuran [THF]) was added to $1 \mathrm{~mL}$ of the Pluronic-PPS NPs $(15 \mathrm{mg} / \mathrm{mL}$ in water) with swirling, and was followed by removal of THF by rotary evaporation, and removal of non-encapsulated OA-USPIOs by filtration through $0.45 \mu \mathrm{m}$ Teflon filters (Whatman Inc, Piscataway, NJ).

\section{Nanoparticle characterization}

Size and $\zeta$-potential of NPs were investigated by dynamic light scattering (DLS) in a Malvern Zetasizer Nano-ZS with the reusable dip-cell kit (Malvern Instruments Ltd, Worcestershire, UK). For measurements of $\zeta$-potential in 
serum media, nanoparticles were mixed with THP-1 growth medium and allowed to incubate at $37^{\circ} \mathrm{C}$ for 24 hours prior to DLS measurements. No further purification of the nanoparticles was performed. This is because the purification process ends up diluting the particles (along with the adsorbed proteins), and may lead to further protein exchange interactions with media used downstream of isolation procedures, as per the Vroman effect. ${ }^{14}$ Therefore, in order to best mimic in vivo conditions, the nanoparticles were measured in the presence of serum. Measurements of hydrodynamic diameter demonstrated the presence of a peak at $<5 \mathrm{~nm}$ that corresponded to proteins, while nanoparticles could still be easily discerned within the 20-100 nm diameter range.

Transmission electron microscopy (TEM) was conducted on a Philips CM20 system (Amsterdam, the Netherlands) operating at $200 \mathrm{kV}$. Carbon film-backed copper grids were inverted onto droplets containing nanoparticle suspensions of interest and blotted dry. Images were collected using a CCD camera with AMT Image Capture Engine software (v 600.335h built on 29 Apr 2010; Advanced Microscopy Techniques, Danvers, MA), and sizing of the particles was automated using a particle analyzer on ImageJ software (v 1.43u). Images were thresholded, and then the built-in (Analyze Particles) function was used to measure the major and minor axes of the fit ellipses around each particle. After artificially discarding clumps of particles encompassed within single fit ellipses (usually identified by major and minor axes that were $>10 \%$ different from one another), or ellipses drawn around globs in the carbon grid (usually identified by any dimension $<1 \mathrm{~nm}$ ), the diameter of individual particles was taken to be the average of the major and minor axis.

For aqueous samples, nanoparticles on TEM grids were also counterstained with $3 \%$ uranyl acetate in water for 2 minutes, gently blotted dry, and dried in a vacuum desiccator for 2 hours prior to imaging.

\section{Cell culture and nanoparticle co-incubation experiments}

Non-adherent THP-1 human leukemic monocytes (American Type Culture Collection, Manassas, VA) were grown in RPMI-1640 medium supplemented with 10\% FBS, 1\% penicillin-streptomycin, $1 \times \mathrm{MEM}$ vitamins (Mediatech, Manassas, VA), $120 \mu \mathrm{M} \beta$-mercaptoethanol, and $10 \mathrm{mM}$ HEPES $^{\circledR}$ (Sigma-Aldrich) at $37^{\circ} \mathrm{C}$ in a $5 \% \mathrm{CO}_{2}$ incubator. For all cell experiments, monocytes were seeded into standard tissue culture-treated plates at a density of 300,000 cells $/ \mathrm{cm}^{2}$, and differentiated for 3 days in growth medium (above) supplemented with $200 \mathrm{nM}$ of phorbol myristate acetate (PMA).
The differentiation process leads to induction of cell adherence onto tissue culture polystyrene surfaces.

For nanoparticle co-incubation experiments, cells were washed once with phosphate buffered saline (PBS) to remove unbound cells, prior to addition of growth medium. The medium was supplemented with nanoparticles and fucoidan. Nanoparticle dosing was based on total iron concentration as measured through the colorimetric phenanthroline assay as previously described..$^{21}$ Final iron concentrations in the wells were calculated to be between $30 \mu \mathrm{M}$ and $200 \mu \mathrm{M}$. For fucoidan competition experiments, media was supplemented with fucoidan to a final concentration of $0-500 \mu \mathrm{M}$.

At selected time points, cells were washed three times with PBS to remove unbound nanoparticles, and then lysed in $3 \mathrm{~N} \mathrm{HCl}$ and $0.25 \%$ Triton X-100 for at least 2 hours. The strongly acidic environment also promotes solubilization of the endocytosed USPIOs via oxidation of the amphiphilic PEG-PPS shell on the nanoparticles into fully hydrophilic polymers, ${ }^{19}$ as well as leaching and mineralization of the iron in the USPIO core. The cell lysate was analyzed for protein content using a commercial Lowry protein assay kit (Bio-Rad Laboratories, Hercules, CA), while iron content was measured using the colorimetric phenanthroline assay as previously described. ${ }^{21}$ While the acidic conditions for the Lowry protein assay deviate significantly from the protocol described by the supplier (alkaline conditions), this does not significantly affect the sensitivity or results of the assay (Supplementary Figure S2).

Calculation of nanoparticle internalization was dependent upon nanoparticle type, as shown in Table 1 . The rationale behind the two different measurement types is inherent to the loading efficiencies possible. Because PEG-PPS-USPIO samples are purified, all cell-nanoparticle interactions in experiments involving them involve an iron "tag". However, since Pluronic-PPS-USPIOs are a subpopulation of the nanoparticles used in this system, not all cell-nanoparticle interactions here involve the iron tag. Due to differing USPIO loading efficiencies across the different Pluronic-PPS surface chemistries available to us, an additional normalization method was required in order that resulting figures fully represented charge-dependent uptake of nanoparticles. The normalization of internalization data to the initially administered dose of iron was therefore used to report internalization of Pluronic-PPS-USPIOs (Table 1).

For cell viability experiments, cells were incubated for 24 hours with PEG-PPS-USPIOs, at a final iron dose of $30 \mu \mathrm{M}, 60 \mu \mathrm{M}$, or $120 \mu \mathrm{M}$. After rinsing cells three times with PBS to remove unbound nanoparticles, they were 
Table I Quantification of nanoparticle uptake into THP-I cells

\begin{tabular}{|c|c|c|c|c|}
\hline Nanoparticle type & Required measurements & Units & Equation & Rationale \\
\hline PEG-PPS-USPIOs & $\begin{array}{l}\text { [Fe] and [Protein] } \\
\text { in cell lysates }\end{array}$ & $\mu \mathrm{g} F / m g$ protein & $\frac{[\mathrm{Fe}]}{[\text { Protein] }}$ & $\begin{array}{l}\text { Result is a quantity normalized to cell number, } \\
\text { but reflects dose-dependence and cell number- } \\
\text { dependence of quantified internalization }\end{array}$ \\
\hline Pluronic-PPS-USPIOs & $\begin{array}{l}{[\mathrm{Fe}] \text { and }[\text { Protein }] \text { in }} \\
\text { cell lysates, and }[\mathrm{Fe}]_{0} \\
\text { (concentration of iron } \\
\text { administered at time } 0 \text { ) }\end{array}$ & $\% / m g$ protein & $\frac{\left(\frac{[\mathrm{Fe}]}{[\mathrm{Fe}]_{0}}\right) \times 100}{[\text { Protein }]}$ & $\begin{array}{l}\text { Different surface chemistries led to differing } \\
\text { loading efficiencies of Pluronic-PPS nanoparticles } \\
\text { with USPIOs. Quantification method enables } \\
\text { experiments to be run at constant nanoparticle } \\
\text { concentrations, without worry of effects of different } \\
\text { loading efficiencies on measured iron internalization }\end{array}$ \\
\hline
\end{tabular}

Notes: PEG-PPS-USPIO internalization data was also represented as \%ID/mg once in this manuscript (Figure 3E) in order to facilitate comparison of results.

Abbreviations: PEG, poly(ethylene glycol); PPS, poly(propylene sulfide); USPIO, ultrasmall superparamagnetic iron oxides.

stained with a commercial calcein-AM/ethidium homodimer live/dead assay kit (Invitrogen, Carlsbad, CA), and quantified according to the manufacturer's instructions.

\section{Protease-activatable nanoparticles}

"Proximity-activated" USPIOs (PA-USPIOs) - which are able to respond to local MMP-9 activity, were formed as described for other PEG-PPS-USPIOs above. For protease experiments, $50 \mu \mathrm{L}$ PA-USPIOs (iron dose $=600 \mu \mathrm{M}$ ) were incubated with $10 \mu \mathrm{L}$ MMP-9 (final concentration $=2 \mu \mathrm{g} / \mathrm{mL})$ in an aqueous buffer containing $0.1 \mathrm{M}$ HEPES, $0.15 \mathrm{M} \mathrm{NaCl}$, and $5 \mathrm{mM} \mathrm{CaCl}_{2}$ (pH 7.2) for 24 hours at $37^{\circ} \mathrm{C}$. For control experiments, PA-USPIOs were incubated with buffer only. Following cleavage, nanoparticles were added directly to cell cultures. The final concentration of iron and MMP-9 in the cell cultures were $120 \mu \mathrm{M}$ and $400 \mathrm{ng} / \mathrm{mL}$, respectively. In some control experiments, MMP-9 inhibitor was also added to the cell cultures, to a final concentration of $300 \mathrm{ng} / \mathrm{mL}$.

\section{Magnetic resonance imaging (MRI)}

MRI was performed on a Varian $4.7 \mathrm{~T}$ horizontal bore imaging system. $T_{2}$ signal decay was measured using a CarrPurcell-Meiboom-Gill (CPMG) spin-echo pulse sequence with $\mathrm{N}=8$ echoes with $6.5 \mathrm{~ms}$ echo spacing. The signal from each voxel at the eight imaging time points was fit to a mono-exponential signal decay model to determine $T_{2}$ for each voxel:

$$
S=S_{0} e^{-\frac{t}{T_{2}}}
$$

A region of interest (ROI) was manually drawn using MATLAB (MathWorks, Inc, Natick, MA) for the first imaging time point and translated to the images from later echoes. The mean $T_{2}$ and standard deviation for each well was then calculated from all voxels within this ROI. Other imaging parameters included TR $=2$ seconds, field of view $=22 \mathrm{~mm} \times 22 \mathrm{~mm}$, data matrix $=128 \times 128$, slice thickness $=1 \mathrm{~mm}$, number of acquisitions $=24$ (total scan time approximately 1 hour 45 minutes).

To prepare cells for MRI, the supernatant containing unbound nanoparticles in medium was aspirated and replaced with PBS, prior to scraping of the cells into the buffer (Corning Life Sciences, Lowell, MA). Cells were centrifuged into a pellet at $300 \mathrm{~g}$ for 5 minutes, and rinsed with PBS twice more. Cells were then fixed with $10 \%$ buffered formalin, gently mixed, and allowed to incubate for 30 minutes at room temperature before they were pelleted and imaged.

\section{Results and discussion}

The primary objective of this study was to investigate sizeand charge-dependent non-specific uptake of nanoparticles by macrophages. With the targeted size range being in the sub$100 \mathrm{~nm}$ hydrodynamic diameter range, the objectives required the synthesis of a library of highly monodisperse, water-soluble nanoparticles in order to reduce size overlap between different nanoparticle formulations and elucidate trends between size and uptake. Therefore, USPIO cores were synthesized by thermal decomposition in organic solvents, which led to oleic acidstabilized USPIOs (OA-USPIOs) of $3.0 \pm 0.4 \mathrm{~nm}$ (Figure 1A, $\mathrm{n}$ approximately 200) and $12.0 \pm 1.0 \mathrm{~nm}$ (Figure 1B, $\mathrm{n}>400$ ). Control over USPIO core diameters was accomplished by adjusting the molar ratios of oleic acid surfactant to iron pentacarbonyl precursor in the reaction feed, and to date, we have synthesized OA-USPIOs of up to $24 \mathrm{~nm}$ in diameter using this method (Supplementary Figure S1). These results extend previous work by Woo et al, ${ }^{22}$ who showed the ability to synthesize particles from $5 \mathrm{~nm}$ to $19 \mathrm{~nm}$ in diameter using this same exact method. Additionally, we were also able to scale up this original synthesis and now are able to produce the uniform OA-USPIOs in $1 \mathrm{~g}$ amounts. 

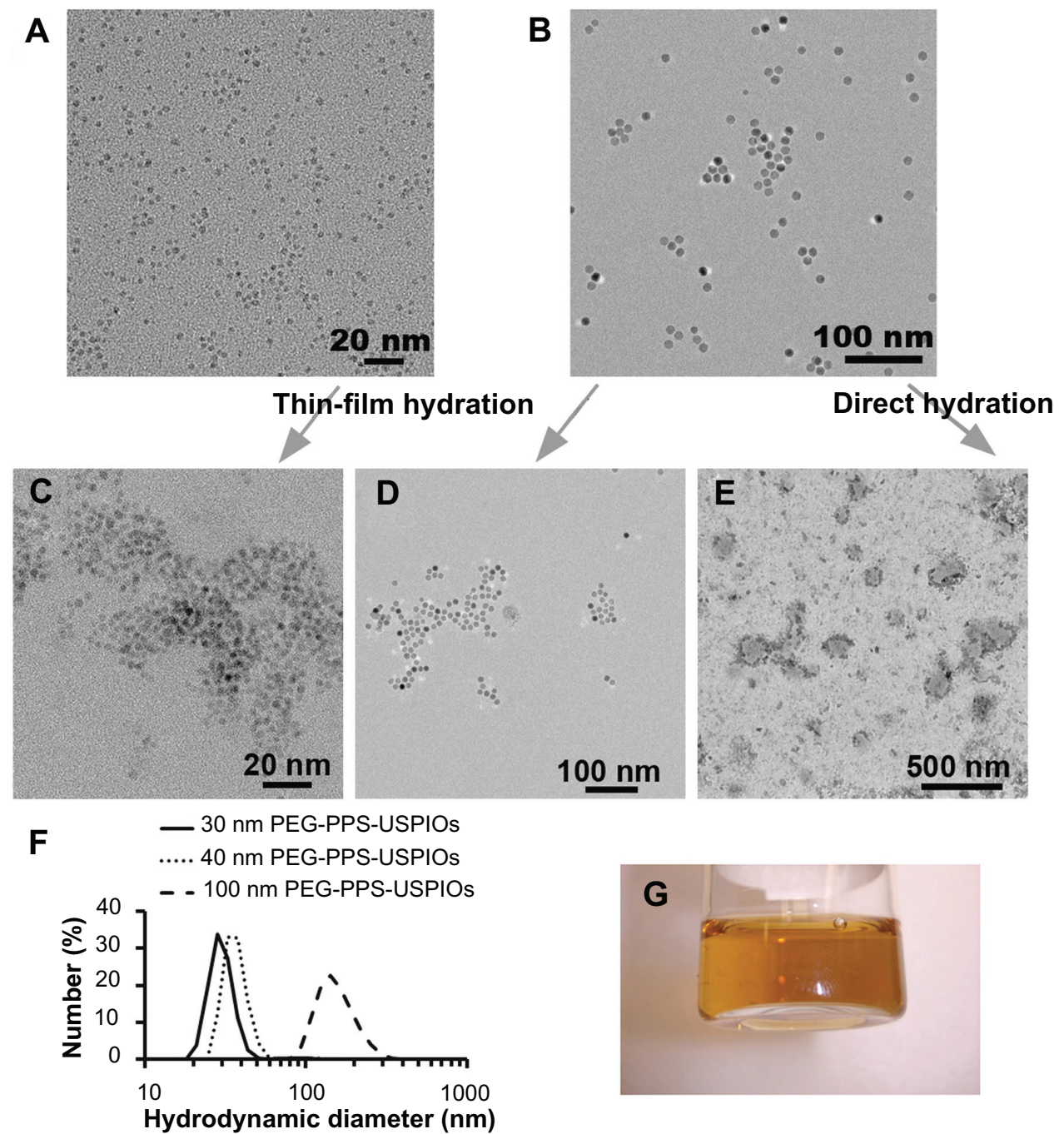

Figure I Characterization of USPIOs and PEG-PPS-USPIO micelles. HRTEM images of $(\mathbf{A}) 3 \mathrm{~nm}$ and (B) 12 nm hydrophobic, oleic acid-stabilized USPIO cores $\left(\gamma\right.$-Fe $\mathrm{O}_{2}$ ), which were synthesized via thermal decomposition. To render particles water-soluble, they were coated with PEG-PPS block copolymers via thin-film hydration to yield, respectively, (C) $30 \mathrm{~nm}$ and (D) $40 \mathrm{~nm}$ PEG-PPS-USPIO micelles. (E) $100 \mathrm{~nm}$ PEG-PPS-USPIO micelles can also be synthesized via direct hydration using the same feed materials used to create micelles in (D); this TEM image has been counterstained with $3 \%$ uranyl acetate. (F) Size-number distributions of these PEG-PPS-USPIO micelles were obtained by dynamic light scattering. (G) As shown in this representative photograph, $40 \mathrm{~nm}$ PEG-PPS-USPIOs remain stable in water and do not flocculate even after storage at room temperature over 4 months.

Note: Scale bars: (A and C) $20 \mathrm{~nm}$; (B and D) $100 \mathrm{~nm}$; (E) $500 \mathrm{~nm}$.

Abbreviations: HRTEM, high resolution transmission electron microscope; PEG, poly(ethylene glycol); PPS, poly(propylene sulfide); TEM, transmission electron spectroscopy; USPIO, ultrasmall superparamagnetic iron oxides.

To render the OA-USPIOs water-soluble, either a thinfilm hydration or a direct hydration method was employed, effectively encapsulating OA-USPIOs within micelles composed of amphiphilic PEG-PPS block copolymers (1.65 kDa PPS block, 4.2 kDa PEG block; Figure 1C-E). Prior to cell experiments, the micelles were sterile-filtered; size-number distributions of the completed USPIO-loaded micelles are shown in Figure 1F. However, due to the larger size of the $100 \mathrm{~nm}$ micelles, these materials tended to be caught in the Teflon filters and were thus used as synthesized. The $30 \mathrm{~nm}$ and $40 \mathrm{~nm}$ micelles were particularly stable in water and flocculated minimally even after storage for several months at room temperature (Figure 1G). These two formulations were also extremely difficult to pellet by centrifugation or through the influence of an externally-applied $1 \mathrm{~T}$ neodymium magnet. The completed micelles exhibited $\zeta$-potentials that were weakly anionic (Table 2), owing partly to the terminal mono-methyl ether group on the PEG block that is displayed on the nanoparticle surface.

Nanoparticles were next administered to THP-1 human leukemic macrophages in order to establish a quantitative basis for the remainder of the experiments, while also examining the kinetics of particle uptake. THP-1 cells were chosen for this study because uptake and processing of lipid nanoparticles by 
Table 2 Size and $\zeta$-potential of as-synthesized PEG-PPS-USPIO micelles

\begin{tabular}{llll}
\hline $\begin{array}{l}\text { Sample } \\
\text { name }\end{array}$ & $\begin{array}{l}\text { USPIO core } \\
\text { diameter }(\mathbf{n m})\end{array}$ & $\begin{array}{l}\text { Micelle diameter } \\
\text { range }(\mathbf{n m})^{\mathbf{a}}\end{array}$ & $\begin{array}{l}\zeta \text {-potential } \\
(\mathbf{m V})\end{array}$ \\
\hline $\begin{array}{l}30 \mathrm{~nm} \text { PEG- } \\
\text { PPS-USPIOs }\end{array}$ & 3 & $30.0 \pm 2.6$ & $-2.8 \pm 5.9$ \\
$40 \mathrm{~nm}$ PEG- & 12 & $36.6 \pm 11.9$ & $-1.7 \pm 4.6$ \\
$\begin{array}{l}\text { PPS-USPIOs } \\
100 \mathrm{~nm} \text { PEG- }\end{array}$ & 12 & & $-7.8 \pm 5.1$ \\
PPS-USPIOs & & & \\
\hline
\end{tabular}

Notes: a Determined after filtration through a $0.45 \mu \mathrm{m}$ PTFE filter. $100 \mathrm{~nm}$ PEGPPS-USPIOs were not as stable to filtration and were not subjected to this additional treatment step prior to use in cell experiments.

Abbreviations: PEG, poly(ethylene glycol); PPS, poly(propylene sulfide); USPIO, ultrasmall superparamagnetic iron oxides.

THP-1 and primary human monocyte-derived macrophages is not significantly different between the two cell types. ${ }^{23,24}$ We expected, therefore, that macrophage interactions with synthetic nanoparticles can be similarly modeled through this readily available, in vitro system.
As an example, varying doses of the $100 \mathrm{~nm}$ PEG-PPSUSPIOs were administered to THP-1 macrophages. Because first-order rate equations are often used as governing equations in efforts to model receptor-mediated endocytosis of nanoparticles by macrophages, ${ }^{25}$ the resulting 24 -hour uptake profiles (Figure 2A) were fit to first-order rate kinetic equations (Figure 2A and B). The successful curve-fit suggested that USPIO concentration is the primary determinant of uptake rate. The best-fit equations take the form:

$$
[C]=[C]_{\max }\left(1-e^{-k t}\right)
$$

where $[C]_{\max }$ represents the maximum possible concentration of iron in the cells and $[C]$ is a measure of the accumulated iron content in the cells. As the fit equations show (Figure $2 \mathrm{~A}$ ), the calculated $[C]_{\max }$ values are proportional to the initially administered doses of PEG-PPS-USPIOs (standard errors $<13 \%$ ), while the calculated rate constants $k$ do not vary significantly across the doses (standard
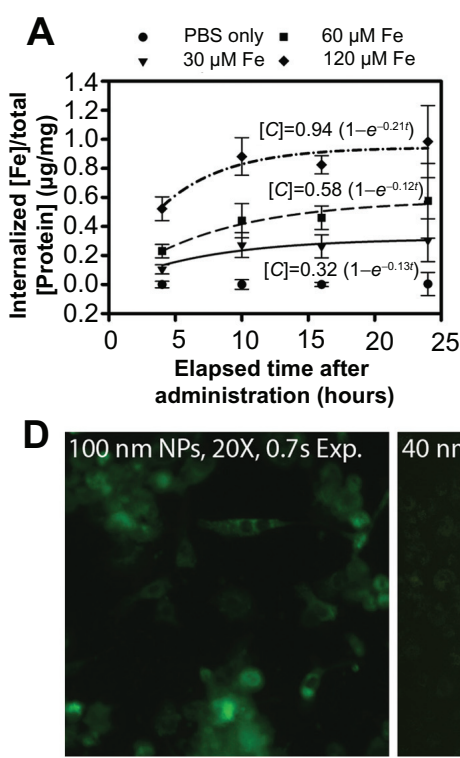

\section{B}

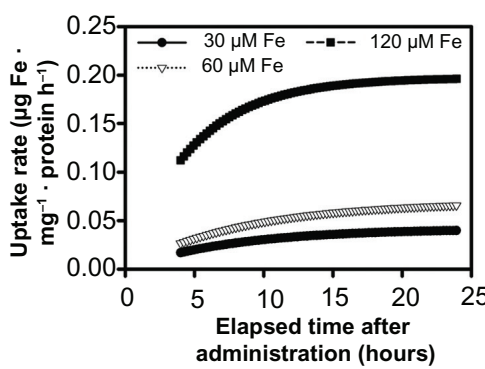

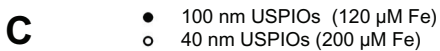
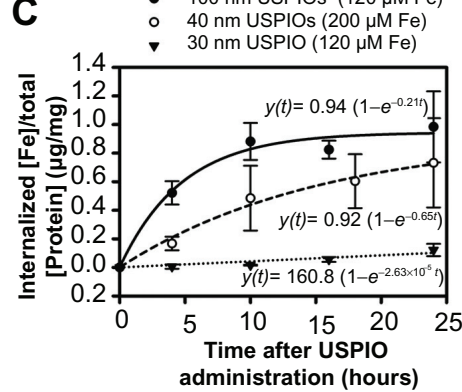

administration (hours)

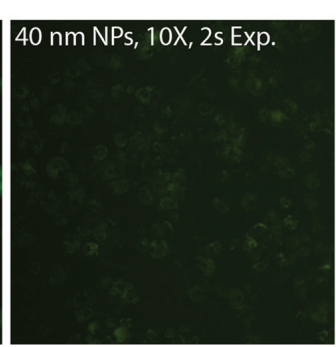

E

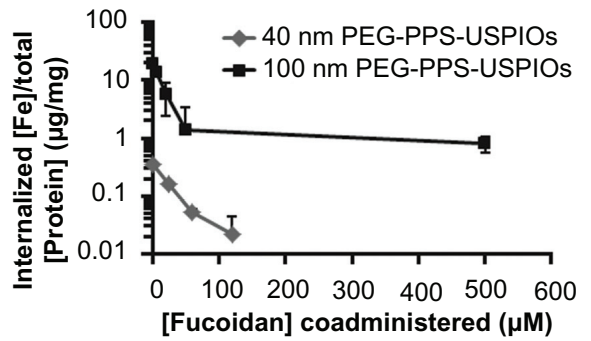

Figure 2 Dose- and size-dependent internalization of PEG-PPS-USPIOs by THP-I macrophages. THP-I cells were treated for up to 24 hours with standard growth serum medium supplemented with varying doses of PEG-PPS-USPIOs in PBS. As a negative control, PBS was used in place of the PEG-PPS-USPIO colloidal suspension. Iron internalization and initial doses were quantified using a colorimetric phenanthroline assay, and internalized iron content was normalized to cell number indirectly via a protein assay. (A) Internalization of nanoparticles over the time period of interest is described by first-order rate kinetics, indicating that initial dose of nanoparticles is the primary determinant of internalization rate and total internalization amount. Relative to the initial doses of USPIOs, macrophages receiving $30 \mu \mathrm{M}, 60 \mu \mathrm{M}$, and $120 \mu \mathrm{M}$ of iron endocytosed $8.4 \% \pm 3.7 \%, 7.7 \% \pm 3.2 \%$, and $6.2 \% \pm 0.9 \%$ of the maximum possible USPIOs, respectively. Error bars indicate standard deviations from six independent experiments. (B) Derivatives of the best-fit kinetic equations plotted in (A) demonstrate further the dependence of uptake rate on initial dose of PEG-PPS-USPIOs. (C) Of the three sizes investigated, $100 \mathrm{~nm}$ nanoparticles were most effectively internalized by the macrophages. Smaller nanoparticles were internalized less effectively, and $30 \mathrm{~nm}$ nanoparticles experienced almost negligible uptake levels over the 24 hour experimental period. Normalization of the 24 hour uptake amounts to the initially administered doses shows that macrophages internalized $6.2 \% \pm 0.9 \%, 1.4 \% \pm 2.3 \%$, and $1.1 \% \pm 0.3 \%$ of the $100 \mathrm{~nm}, 40 \mathrm{~nm}$, and $30 \mathrm{~nm}$ PEG-PPS-USPIOs, respectively. Error bars represent standard deviation from three to six independent experiments. (D) Fluorescent imaging of the delivery of $40 \mathrm{~nm}$ and $100 \mathrm{~nm}$ fluorescent PEG-PPS-USPIO micelles. The uptake of I00 nm nanoparticles was easily visualized at $20 \times$ magnification with a 0.7 second exposure time, but even with a lower magnification and roughly a three-fold higher exposure time, the microscope was insufficiently sensitive to visualize the internalization of the $40 \mathrm{~nm}$ nanoparticles. (E) $40 \mathrm{~nm}$ PA-USPIOs (at $200 \mu$ M Fe) or $100 \mathrm{~nm}$ PEG-PPS-USPIOs (at $120 \mu \mathrm{M} \mathrm{Fe}$ ) were co-administered to THP-I macrophages with varying amounts of fucoidan for 24 hours, and allowed to incubate overnight prior to cell lysis and measurement of internalized iron. Increasing concentrations of fucoidan correlated with decreased uptake of the nanoparticles, suggesting that the mechanism of PEG-PPS-USPIO uptake is via receptor-mediated endocytosis, and facilitated by the scavenger receptor CD204. Error bars represent standard deviation of three independent experiments.

Abbreviations: PA-USPIOs, proximity-activated ultrasmall superparamagnetic iron oxides; PBS, phosphate buffered saline; PEG, poly(ethylene glycol); PPS, poly(Propylene sulfide); THP, human acute monocytic leukemia cell line. 
errors $25 \%-40 \%$ ). Relative to the initial doses of USPIOs, macrophages receiving $30 \mu \mathrm{M}, 60 \mu \mathrm{M}$, and $120 \mu \mathrm{M}$ of iron endocytosed $8.4 \% \pm 3.7 \%, 7.7 \% \pm 3.2 \%$, and $6.2 \% \pm 0.9 \%$ of the maximum possible USPIOs, respectively. In order to ensure that the measurements excluded USPIO binding events not resulting in uptake, some experiments were also conducted at $4{ }^{\circ} \mathrm{C}$ to block endocytosis, resulting in insignificant iron levels quantified in the lysates (Supplementary Figure S3). In addition, a live/dead cytotoxicity assay was also conducted in order to confirm that treatment of macrophages with the PEG-PPS-USPIOs resulted in minimal cell death (Supplementary Figure S4).

Similar nanoparticle uptake kinetics were also observed for particles of smaller hydrodynamic diameters (Figure 2C). The results also show that by mass, smaller nanoparticles are internalized less effectively than their larger counterparts. The $40 \mathrm{~nm}$ nanoparticles shown in this graph were based on a higher iron dose for easier visualization; however, the same nanoparticles, administered at the same $120 \mu \mathrm{M}$ Fe dose as the other two samples, were internalized at $0.36 \pm 0.55 \mu \mathrm{g} / \mathrm{mg}$ protein (curve not shown). Normalization of the 24-hour uptake data to the initially administered doses shows that THP-1 macrophages were able to internalize $1.1 \% \pm 0.3 \%$, $1.4 \% \pm 2.3 \%$, and $6.2 \% \pm 0.9 \%$ of the $30 \mathrm{~nm}, 40 \mathrm{~nm}$, and $100 \mathrm{~nm}$ PEG-PPS-USPIOs, respectively. When nanoparticle internalization is normalized to cell number, a 70\% decrease in PEG-PPS-USPIO diameter corresponded with almost a ten-fold decrease in iron uptake per cell. This was supported by fluorescence microscopy experiments, where macrophages were treated with FITC-tagged nanoparticles (Figure 2D), demonstrating the accumulation of $100 \mathrm{~nm}$ micelles within the macrophages. Despite longer exposure times at a lower magnification, the microscope was insufficiently sensitive to visualize the internalization of the $40 \mathrm{~nm}$ micelles by the macrophages. Taken together, these data suggest a positive correlation between nanoparticle size and their non-specific recognition and internalization by macrophages.

Given the lack of any specific targeting moieties on the micelle surface, this evidence suggested that within the nanoparticle size range investigated, macrophages were able to optimally recognize and internalize PEGylated nanoparticles of $>100 \mathrm{~nm}$ diameter. Further, smaller nanoparticles seemed to experience significantly less non-specific uptake by the macrophages. One of the mechanisms of uptake is likely through receptor-mediated endocytosis via CD204-as PEG-PPS-USPIO internalization can be effectively blocked by co-administration of nanoparticles with fucoidan, which is a well-known CD204 ligand (Figure 2E). ${ }^{4}$
We next investigated the effects of nanoparticle charge on non-specific uptake. Because the sub-40 nm nanoparticles provided a satisfactorily minimal baseline uptake over 24 hours, we opted to focus on nanoparticles of this size for this section of the study. End-carboxylated, -aminated, and -thiolated Pluronic were used as surfactants in inverse emulsion polymerization as described previously. ${ }^{10}$ The resulting Pluronic-PPS nanoparticles were loaded with USPIOs via direct hydration (Figure $3 \mathrm{~A}-\mathrm{C}$ ), and delivered to THP-1 macrophages under the same conditions described for the other cell experiments above. Since Pluronic polymers are PEG-containing block co-polymers, the properties of Pluronic-PPS are not very different from those of PEG-PPS used in the other studies shown here, and, in effect, still produce PEG-PPS-coated USPIOs. Pluronic-PPS enables facile synthesis schemes necessary to produce the various endfunctionalized polymers used in this work that would otherwise be more difficult to generate from PEG-PPS coatings. ${ }^{19}$

In order to account for differences in USPIO loading efficiencies across the library of Pluronic-PPS nanoparticle formulations, uptake was not only reported as [Fe]/[Protein] as above, but further normalized to initial doses of iron and reported as percent injected dose/protein $(\% \mathrm{ID} / \mathrm{mg}$ protein; Figure 3D, Table 1). We hypothesized that this system would enable us to parse out the roles of surface charge from size on nanoparticle internalization, leading us to identify the sensitivity of size and charge on nanoparticle non-specific uptake by macrophages.

The Pluronic-PPS-USPIOs initially exhibited surface charges from $-23 \mathrm{mV}$ up to $+9 \mathrm{mV}$, but following incubation in $10 \%$ serum media for 4 hours, all nanoparticle formulations experienced significant changes in $\zeta$ potential (Figure 3D). Therefore, while the $\zeta$ potential of the nanoparticles was tunable to some extent by varying the surface chemistry of the nanoparticles, electrostatic interactions with serum proteins and components, as well as protein adsorption and opsonization processes contributed to significant changes in nanoparticle properties. The addition of serum into the incubation medium for these studies is intended to reflect an interaction environment that includes important components of the in vivo environment. Since there is no opportunity for nanoparticle purification following intravenous injection, we elected to allow nanoparticle interaction with serum proteins during $\zeta$ potential measurements, and later on, incubation with THP-1 cells. One outcome of this approach, and equally true in vivo, is the modulation of initial nanoparticle $\zeta$ potential by serum protein adsorption. These processes have been studied in detail for the Pluronic-PPS nanoparticle system, as 

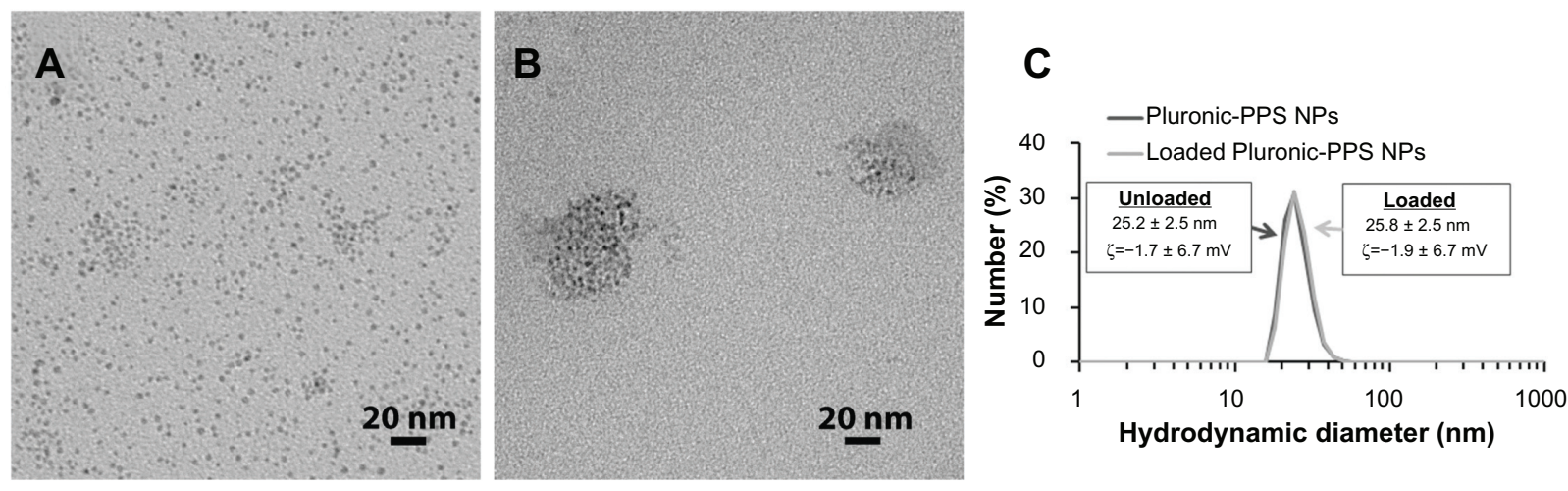

D

E

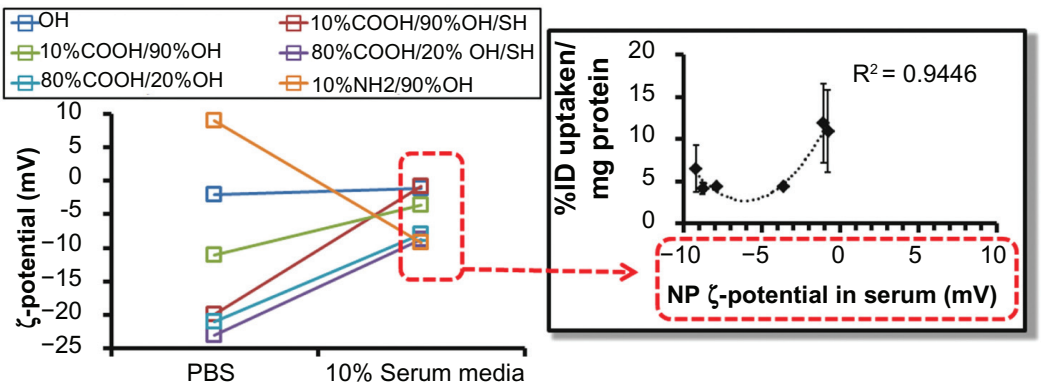

Solvent for NP $\zeta$-potential measurement

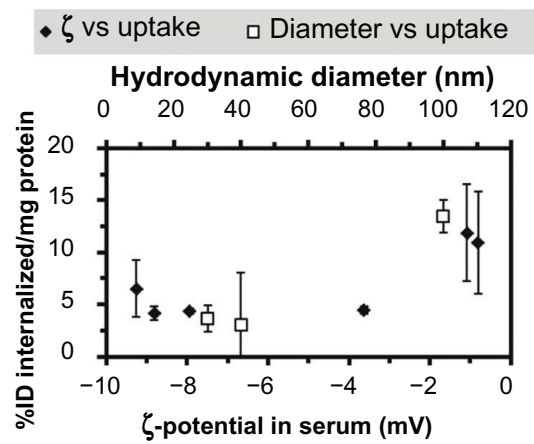

Figure 3 Effects of nanoparticle surface charge and chemistry on macrophage uptake. Representative TEM images of (A) hydrophobic, unloaded 3 nm OA-USPIOs and (B) water-soluble Pluronic-PPS nanoparticles after loading with the OA-USPIOs. (C) The loading process does not significantly affect the hydrodynamic diameters or the $\zeta$ potentials inherent to the Pluronic-PPS nanoparticles. (D) $\zeta$-potential of all nanoparticle formulations (color-coded by surface chemistry) was originally measured in PBS following synthesis, and again following incubation in 10\% serum media. While modulation of surface chemistry allows for a wide range of $\zeta$-potentials, this range is compressed due to interactions between nanoparticles and media components. Uptake of nanoparticles correlated with their surface charge as measured in media (inset; red dotted boxes indicate source of data for x-axis), according to a parabolic distribution. To account for differences in USPIO loading efficiency across the different PluronicPPS nanoparticle formulations, nanoparticle uptake was normalized to the initial dose administered as well as cell content indirectly, via a protein assay. Error bars indicate standard deviation for three independent experiments. (E) Cell internalization data is plotted versus nanoparticle $\zeta$-potentials measured in $10 \%$ serum media (solid squares). In order to determine which nanoparticle feature may be more determinant of non-specific interactions with macrophages, the effects of nanoparticle diameter have also been plotted for comparison (open squares).

Abbreviations: OA-USPIOs, oleic acid-stabilized ultrasmall superparamagnetic iron oxides; PBS, phosphate buffered saline; PPS, poly(propylene sulfide); TEM, transmission electron microscopy.

reported by Thomas et al. ${ }^{10}$ In particular, varying the surface chemistry of this nanoparticle system influenced the ability of the nanoparticles to become functionalized with the $\mathrm{C} 3$ complement proteins. ${ }^{10}$ More generally, this phenomena is well known in the synthetic gene delivery field, in which cationic nanoscale carriers of pDNA or siRNA rapidly interact with albumin and other serum proteins in vivo, and is consistent with the findings reported here. ${ }^{26}$ This is significant because many consider that a minimum $\zeta$ potential of $\pm 30 \mathrm{mV}$ is necessary in order to form stable nanoparticle suspensions. ${ }^{27}$ Because electrostatic interactions and adsorption processes between serum proteins and the nanoparticle surface are inevitable following in vivo administration, higher $\zeta$ potential magnitudes may actually promote these processes, and in turn, opsonization processes ultimately leading to nanoparticle clearance from the bloodstream.

The observed decrease in the magnitude of the nanoparticle $\zeta$ potentials did not correspond with increased agglomeration, as no flocculation or sedimentation was observed in any of the samples following treatment with serum. This observation was true of all nanoparticle formulations regardless of surface chemistry, possibly owing to the colloidal stability of Pluronic-PPS nanoparticles as shown previously. ${ }^{19}$

The two formulations that were most efficiently internalized were the nanoparticles displaying the terminal $\mathrm{OH}(12 \% \pm 5 \% \mathrm{ID} / \mathrm{mg}$ protein) and the $10 \% \mathrm{COOH} / 90 \%$ $\mathrm{OH} / \mathrm{SH}(11 \% \pm 5 \% / \mathrm{mg})$. Uptake correlated with nanoparticle charge as measured in serum, yielding a parabolic trend with maximum uptake observed for cationic and strongly anionic nanoparticles (Figure $3 \mathrm{D}, R^{2}=0.94$, inset). However, because interactions with serum compressed the range of nanoparticle $\zeta$ potentials, we were unable to experimentally explore uptake of the nanoparticles beyond the $-10 \mathrm{mV}$ to $0 \mathrm{mV}$ range. Despite the narrow window of $\zeta$ potentials covered by the data, the trends suggest that 
non-specific uptake of nanoparticles may be promoted by nanoparticle cationicity or high anionicity. This is consistent with previous observations. ${ }^{13}$

Uptake of nanoparticles in serum was minimized in the range of $\zeta$ potentials from $-9.0 \mathrm{mV}$ to $-3.5 \mathrm{mV}$. A threefold increase in uptake was measured for identically sized nanoparticles having $\zeta$ potentials in serum from $-3.5 \mathrm{mV}$ to $-0.8 \mathrm{mV}$, representing a $77 \%$ decrease in anionicity. In comparison, a four-fold change in uptake was observed for a $60 \%$ decrease in PEG-PPS-USPIO diameter $(100 \mathrm{~nm}$ to $40 \mathrm{~nm}$ ). Over these ranges and conditions, macrophage uptake of these nanoparticles is $42 \%$ more sensitive to size than to $\zeta$ potential (Figure $3 \mathrm{E}$ ).

To expand on this conclusion, we synthesized PEG-PPSUSPIOs containing an MMP-9-degradable peptide (M9C) within the PEG chain (Figure 4A and B). This design results in particles that respond to active MMP-9 in the environment by releasing a layer of PEG, effectively leading to a decrease in nanoparticle diameter. Probes for MMP-9 activity are of wide interest because of the upregulation of MMP-9 in the progression of atherosclerosis. ${ }^{28-30}$ Based on the studies described earlier, we hypothesized that this experimental contrast agent would experience less uptake by macrophages following treatment with MMP-9, relative to the as-synthesized, intact form.

These MMP-9-responsive contrast agents were synthesized by encapsulating $10 \mathrm{~nm}$ and $3 \mathrm{~nm}$ OA-USPIOs using approximately 10 kDa mPEG-[M9C]-PEG-PPS (subsequently referred to as "PA" for protease-activatable), to produce $60 \mathrm{~nm}$ and $30 \mathrm{~nm}$ PA-USPIOs (Figure 4C and D). Both PA-USPIO formulations responded to MMP-9 treatment with a 10-20 nm decrease in nanoparticle hydrodynamic diameters as measured by DLS, while $\zeta$-potentials were not significantly affected (30 nm PA-USPIOs: $-3.9 \pm 6.4 \mathrm{mV}$ pre-cleavage, $-2.8 \pm 5.9 \mathrm{mV}$ post-cleavage; $60 \mathrm{~nm}$ PAUSPIOs: $0.0 \pm 7.1 \mathrm{mV}$ pre-cleavage, $-4.7 \pm 5.5 \mathrm{mV}$ postcleavage). For cell experiments, PA-USPIOs were incubated with MMP-9 for 24 hours prior to their administration to THP-1 cells at equivalent iron doses. In both cases, MMP9-treated PA-USPIOs were internalized significantly less effectively than their non-cleaved counterparts (Figure 4E). Most notably, the $30 \mathrm{~nm}$ PA-USPIOs experienced a sixfold decrease in nanoparticle uptake following MMP-9 cleavage $(0.12 \pm 0.04 \mu \mathrm{g} \mathrm{Fe} / \mathrm{mg}$ protein pre-cleavage vs $0.02 \pm 0.02 \mu \mathrm{g} / \mathrm{mg}$ post-cleavage). Also of note is the slightly higher uptake of the MMP-9-treated $60 \mathrm{~nm}$ PA-USPIOs (final diameter $=40.0 \pm 6.2 \mathrm{~nm}$ ) relative to the untreated $30 \mathrm{~nm}$ PA-USPIOs $(30.0 \pm 2.6 \mathrm{~nm})$.
Because these changes in nanoparticle internalization may be due to MMP-9-mediated modifications on the cell membranes, a series of control experiments were also performed, using non-cleavable, $40 \mathrm{~nm}$ PEG-PPS-USPIOs (Supplementary Figure S5). In these experiments, co-administration of non-cleavable nanoparticles with MMP-9 did not lead to significant differences in nanoparticle internalization. Further, co-administration with a MMP-9 inhibitor also did not affect internalization. Taken together, the results suggest that the variations in PA-USPIO internalization by the THP-1 cells were attributable to the size of the nanoparticles, as the nanoparticle $\zeta$ potentials did not vary significantly before versus after treatment with MMP-9. Further, cellular capacity for nanoparticle internalization was unaffected by exposure to protease.

To determine if these MMP-9-dependent differences in nanoparticle internalization result in statistically significant changes in sample $T_{2}$ relaxation, and therefore, clinically relevant detection of MMP-9 activity in cell samples, $60 \mathrm{~nm}$ PA-USPIO-treated cells were pelleted and imaged on a 4.7 $\mathrm{T}$ magnetic resonance imaging scanner (Figure 4F). Through the use of a CPMG spin-echo pulse sequence, MMP-9-treated PA-USPIOs appeared to exhibit higher mean gray intensities versus cells incubated with untreated PA-USPIOs.

While the PA-USPIOs exhibited $T_{2}=4.82 \pm 0.02 \mathrm{~ms}$, the PA-USPIOs on the macrophages exhibited $T_{2}=23.2 \pm 3.5 \mathrm{~ms}$. These rather strong changes in $T_{2}$ are somewhat surprising assuming that approximately $1 \%$ of the administered dose was taken up by the macrophages as measured in the earlier sections of this work. This implies that for each imaging slice, the concentration of iron responsible for $T_{2}$ signal modulation within that slice is about 100 -fold less in the nanoparticle-treated cell samples versus the positive control. To quantify this phenomenon, the calculated values above (from first-principle measurements) can be plugged into the $R_{2}$ relaxivity equation:

$$
R_{2}=\frac{1}{T_{2} \times[\mathrm{Fe}]}
$$

in order to produce a measure of how effective the USPIOs are in modulating the local negative contrast. Given that measured $T_{2}$ in the cell samples is only approximately five times higher than the measurements in the positive control, the iron concentration in the cell samples would need to be about a fifth of the concentration in the positive control in order to maintain the same $R_{2}$ value. As we have seen, this 
A

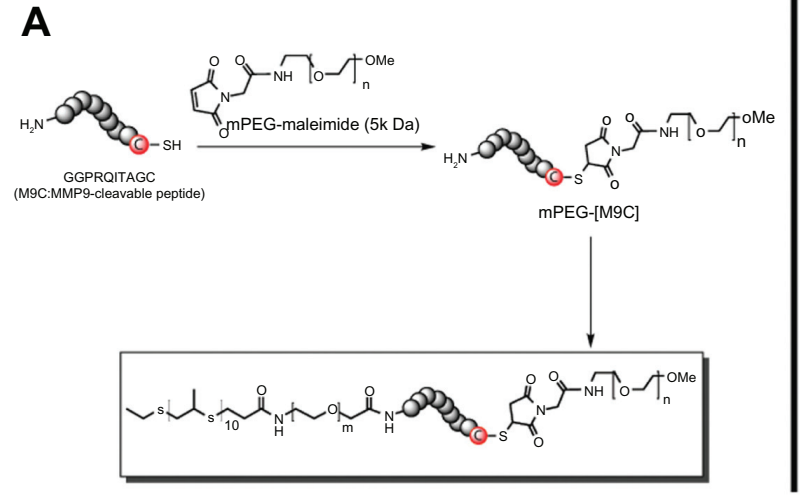

C

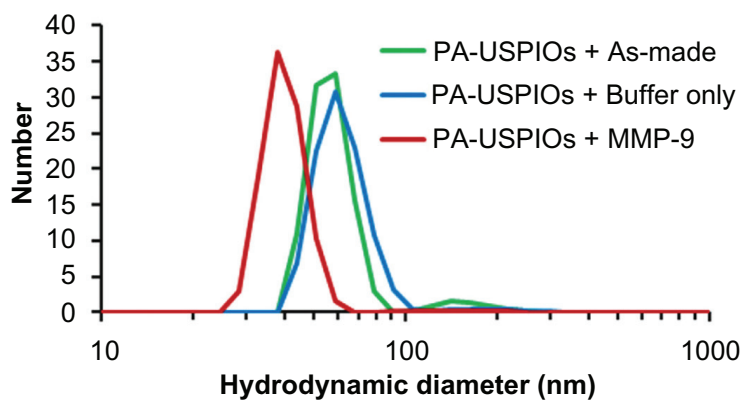

E

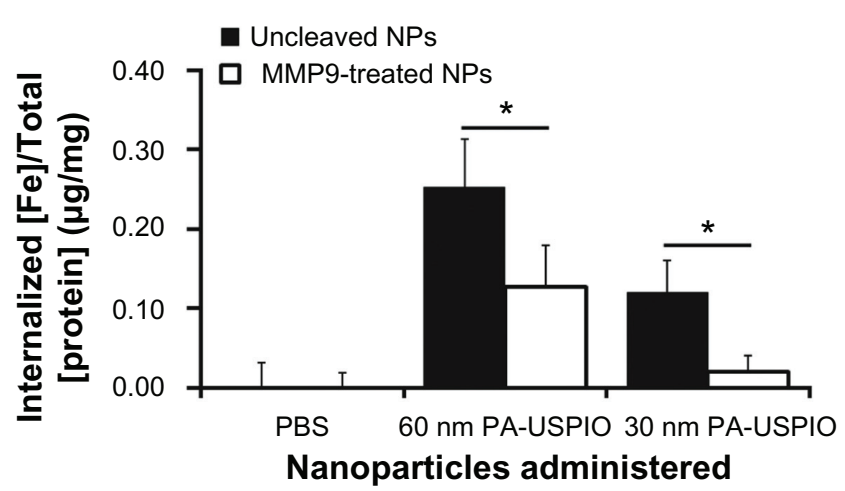

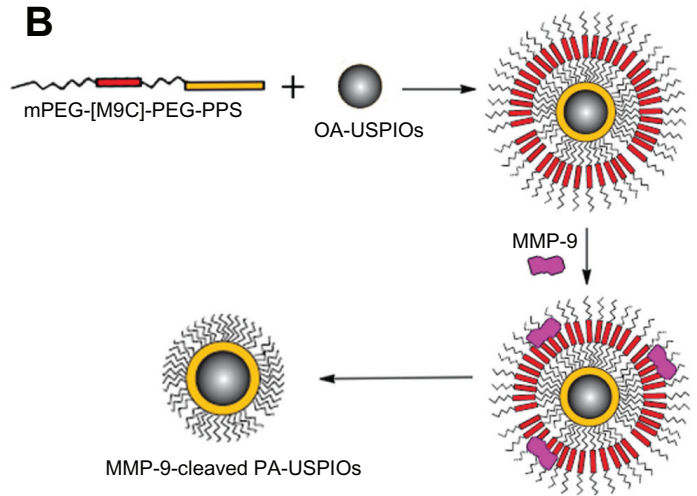

D

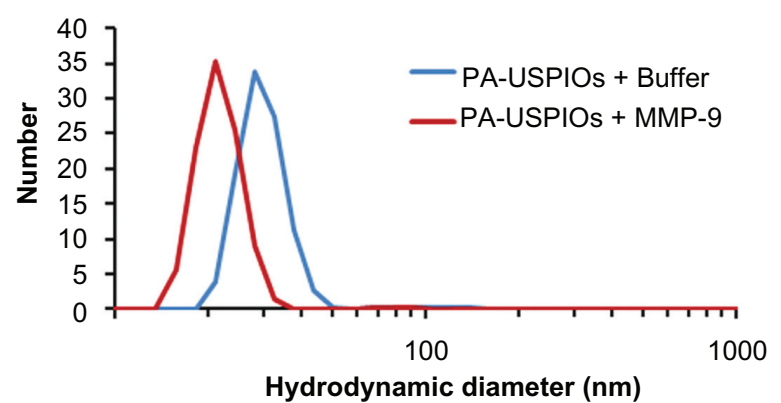

$\mathbf{F}$

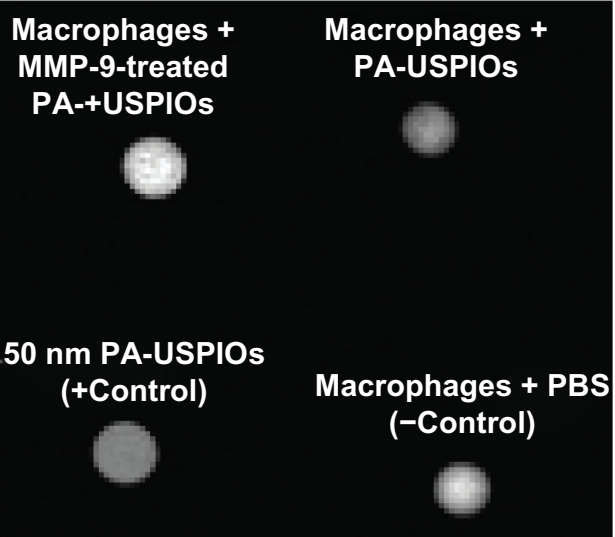

Figure 4 Behavior of MMP-9-responsive PA-USPIOs. (A) Synthesis of MMP-9-cleavable PEG-PPS chains (mPEG-[M9C]-PEG-PPS; PA) and (B) encapsulation of USPIOs to form PA-USPIOs. MMP-9 is able to recognize and cleave the (M9C) peptide sequence, resulting in release of a layer of PEG from the nanoparticle surface, accompanied by a decrease in nanoparticle hydrodynamic diameter. (C) DLS characterization of hydrodynamic diameters of as-synthesized $60 \mathrm{~nm}$ PA-USPIOs (C; green) and $30 \mathrm{~nm}$ PAUSPIOs (D; blue) demonstrates a loss in hydrodynamic diameter following treatment with MMP-9. (E) Buffer-treated or MMP-9-pretreated nanoparticles were delivered to THP-I macrophages for 24 hours in standard growth medium. As a control, PBS was used in place of the nanoparticles. For both PA-USPIO formulations tested, the decrease in nanoparticle size following MMP-9 treatment results in less effective nanoparticle internalization by the macrophages. Error bars represent standard deviations from three to six independent experiments. (F) $T_{2}$-weighted MRI of THP-I cells treated with MMP-9-cleaved PA-USPIOs appeared brighter than cells incubated with untreated PAUSPIOs, indicating that less cleaved nanoparticles were internalized by the macrophages versus the untreated PA-USPIOs.

Note: $* P<0.05$ by Student's t-test.

Abbreviations: DLS, dynamic light scattering; MMP-9, matrix metalloproteinase-9; PA-USPIOs, proximity-activated ultrasmall superparamagnetic iron oxides; MRI, magnetic resonance imagery; PBS, phosphate buffered saline; PEG, poly(ethylene glycol); PPS, poly(propylene sulfide).

is hardly the case, and based on our data, we can conclude that the $R_{2}$ values in the cell sample would have to be on the order of 20-fold larger than the $R_{2}$ of the free-floating PA-USPIOs. These results indicate that following internalization by the macrophages, the PA-USPIOs are being manipulated in such a way that increases their ability to exert $T_{2}$ contrast.
This phenomenon can be explained by previous observations that aggregated or clustered superparamagnetic nanoparticles result in higher $R_{2}$ versus fully dispersed, singlet nanoparticles. ${ }^{16,31}$ Others have demonstrated via TEM that following endocytosis of iron oxide nanoparticles, macrophages can process the particles into lysosomes, where dense clusters of particles can usually be observed. ${ }^{32}$ 
Taken together, these other observations help explain how even a small amount of nanoparticle uptake results in a marked change in $T_{2}$ contrast in the system.

\section{Conclusion}

PEGylated nanoparticles are internalized by macrophages in a size-dependent fashion for diameters between $30 \mathrm{~nm}$ and $100 \mathrm{~nm}$. Charge-uptake relationships were investigated by varying the surface properties of nanoparticles. While the data supports the possibility that cationic and strongly anionic nanoparticles may be internalized most effectively, within the ranges investigated, nanoparticle size, not charge, is a stronger determinant of non-specific uptake by macrophages. Based on this information, an MMP-9-sensitive nanoparticle was developed that decreases in size following treatment with MMP-9. Macrophages respond to MMP-9-treated nanoparticles in a predictable fashion, and cleaved nanoparticles were consistently phagocytosed less efficiently than their untreated counterparts, demonstrating the effects of dynamic nanoparticle size modulation on macrophage uptake. These MMP-9-induced differences in uptake are also detectable via MRI. Despite the low levels of overall uptake over the 24 hour incubation periods ( $\leq 1 \%$ initially administered dose), a significant increase in macrophage $R_{2}$ was observed. Presumably, and consistent with quantitative analysis, the clustering of nanoparticles into endosomes following endocytosis results in an increase in nanoparticle $R_{2}$, providing amplification of negative MR image contrast. The results presented here inform the design of nanoparticles to target or evade macrophages in future in vivo applications.

\section{Acknowledgments}

This work was supported by a Vanderbilt University Intramural Discovery Grant (4-48-999-9132), the Department of Defense Congressionally Directed Medical Research Programs (W81XWH-08-1-0502), and a Whitaker International Scholarship to SNT. CML acknowledges support through a fellowship from the Vanderbilt University Undergraduate Summer Research Program (VUSRP). Dynamic light scattering and TEM were conducted through the use of the core facilities of the Vanderbilt Institute of Nanoscale Sciences and Engineering (VINSE), using facilities renovated under NSF ARI-R2 DMR-0963361. We thank Dr Daniel Colvin of the Vanderbilt University Institute of Imaging Science (VUIIS) for his assistance with MRI imaging and analysis. We also acknowledge the laboratories of Professors Hak-Joon Sung and Craig L Duvall (Vanderbilt Biomedical Engineering), whose equipment were instrumental to the execution of this work.

\section{Disclosure}

The authors have no conflicts of interest to disclose.

\section{References}

1. Martin P. Wound healing - aiming for perfect skin regeneration. Science. 1997;276(5309):75-81.

2. Bouwens L, Baekeland M, De Zanger R, Wisse E. Quantitation, tissue distribution and proliferation kinetics of Kupffer cells in normal rat liver. Hepatology. 1986;6(4):718-722.

3. Felix R, Cecchini MG, Hofstetter W, Elford PR, Stutzer A, Fleisch H. Impairment of macrophage colony-stimulating factor production and lack of resident bone marrow macrophages in the osteopetrotic op/op Mouse. J Bone Miner Res. 1990;5(7):781-789.

4. Brown MS, Goldstein JL. Lipoprotein metabolism in the macrophage: implications for cholesterol deposition in atherosclerosis. Annu Rev Biochem. 1983;52:223-261.

5. Linehan SA, Martinez-Pomares L, Gordon S. Mannose receptor and scavenger receptor: two macrophage pattern recognition receptors with diverse functions in tissue homeostasis and host defense. Adv Exp Med Biol. 2000;479:1-14.

6. Kindt TJ, Goldsby RA, Osborne BA, Kuby J. Kuby Immunology. 6th ed. New York: W.H. Freeman; 2007.

7. Plüddemann A, Neyen C, Gordon S. Macrophage scavenger receptors and host-derived ligands. Methods. 2007;43(3):207-217.

8. Chnari E, Nikitczuk JS, Wang J, Uhrich KE, Moghe PV. Engineered polymeric nanoparticles for receptor-targeted blockage of oxidized low density lipoprotein uptake and atherogenesis in macrophages. Biomacromolecules. 2006;7(6):1796-1805.

9. Lipinski MJ, Amirbekian V, Frias JC, et al. MRI to detect atherosclerosis with gadolinium-containing immunomicelles targeting the macrophage scavenger receptor. Magn Reson Med. 2006;56(3):601-610.

10. Thomas SN, van der Vlies AJ, O’Neil CP, et al. Engineering complement activation on polypropylene sulfide vaccine nanoparticles. Biomaterials. 2011;32(8):2194-2203.

11. Doshi N, Mitragotri S. Macrophages recognize size and shape of their targets. PLoS One. 2010;5(4):e10051.

12. Taylor PR, Brown GD, Herre J, Williams DL, Willment JA, Gordon S. The role of SIGNR1 and the beta-glucan receptor (dectin-1) in the nonopsonic recognition of yeast by specific macrophages. J Immunol. 2004;172(2):1157-1162.

13. Raynal I, Prigent P, Peyramaure S, Najid A, Rebuzzi C, Corot C. Macrophage endocytosis of superparamagnetic iron oxide nanoparticles: mechanisms and comparison of ferumoxides and ferumoxtran-10. Invest Radiol. 2004;39(1):56-63.

14. Ratner BD. Biomaterials Science: an Introduction to Materials in Medicine. San Diego, CA: Academic Press; 1996.

15. Velluto D, Demurtas D, Hubbell JA. PEG-b-PPS diblock copolymer aggregates for hydrophobic drug solubilization and release: cyclosporin A as an example. Mol Pharm. 2008;5(4):632-642.

16. Yu SS, Scherer RL, Ortega RA, et al. Enzymatic- and temperaturesensitive controlled release of ultrasmall superparamagnetic iron oxides (USPIOs). J Nanobiotechnology. 2011;9:7.

17. Deguchi JO, Aikawa M, Tung CH, et al. Inflammation in atherosclerosis: visualizing matrix metalloproteinase action in macrophages in vivo. Circulation. 2006;114(1):55-62.

18. Chan WC, White PD, editors. Fmoc Solid Phase Peptide Synthesis: a Practical Approach. Oxford, UK: Oxford University Press; 2000.

19. Rehor A, Hubbell JA, Tirelli N. Oxidation-sensitive polymeric nanoparticles. Langmuir. 2005;21(1):411-417.

20. van der Vlies AJ, O’Neil CP, Hasegawa U, Hammond N, Hubbell JA. Synthesis of pyridyl disulfide-functionalized nanoparticles for conjugating thiol-containing small molecules, peptides, and proteins. Bioconjug Chem. 2010;21(4):653-662.

21. Christian GD. Analytical Chemistry. 5th ed. New York: Wiley \& Sons; 1994. 
22. Woo K, Hong J, Choi S, et al. Easy synthesis and magnetic properties of iron oxide nanoparticles. Chem Mater. 2004;16(14):2814-2818.

23. Griffin EE, Ullery JC, Cox BE, Jerome WG. Aggregated LDL and lipid dispersions induce lysosomal cholesteryl ester accumulation in macrophage foam cells. J Lipid Res. 2005;46(10):2052-2060.

24. Jerome WG, Cox BE, Griffin EE, Ullery JC. Lysosomal cholesterol accumulation inhibits subsequent hydrolysis of lipoprotein cholesteryl ester. Microsc Microanal. 2008;14(2):138-149.

25. Ece Gamsiz D, Shah LK, Devalapally H, Amiji MM, Carrier RL. A model predicting delivery of saquinavir in nanoparticles to human monocyte/macrophage (Mo/Mac) cells. Biotechnol Bioeng. 2008;101(5):1072-1082.

26. Phillips NC, Heydari C. Modulation of cationic liposomal DNA zeta potential and liposome-protein interaction by amphiphilic poly (ethylene glycol)*. Pharm Pharmacol Commun. 1996;2(2):73-76.

27. Han F, Li S, Yin R, Liu H, Xu L. Effect of surfactants on the formation and characterization of a new type of colloidal drug delivery system: nanostructured lipid carriers. Colloids Surf A: Physicochem Eng Asp. 2008;315(1-3):210-216
28. Gough PJ, Gomez IG, Wille PT, Raines EW. Macrophage expression of active MMP-9 induces acute plaque disruption in apoE-deficient mice. J Clin Invest. 2006;116(1):59-69.

29. Schellenberger E, Rudloff F, Warmuth C, Taupitz M, Hamm B, Schnorr J. Protease-specific nanosensors for magnetic resonance imaging. Bioconjug Chem. 2008;19(12):2440-2445.

30. Sluijter JP, Pulskens WP, Schoneveld AH, et al. Matrix metalloproteinase 2 is associated with stable and matrix metalloproteinases 8 and 9 with vulnerable carotid atherosclerotic lesions: a study in human endarterectomy specimen pointing to a role for different extracellular matrix metalloproteinase inducer glycosylation forms. Stroke. 2006;37(1):235-239.

31. Perez JM, O’Loughin T, Simeone FJ, Weissleder R, Josephson L. DNAbased magnetic nanoparticle assembly acts as a magnetic relaxation nanoswitch allowing screening of DNA-cleaving agents. $J \mathrm{Am}$ Chem Soc. 2002;124(12):2856-2857.

32. Müller K, Skepper JN, Posfai M, et al. Effect of ultrasmall superparamagnetic iron oxide nanoparticles (Ferumoxtran-10) on human monocyte-macrophages in vitro. Biomaterials. 2007;28(9):1629-1642. 


\section{Supplementary figures}

Online supplementary materials include the following Figures: (S1) control over iron oxide nanoparticle size, (S2) Lowry protein assay standard curves, (S3) nanoparticle

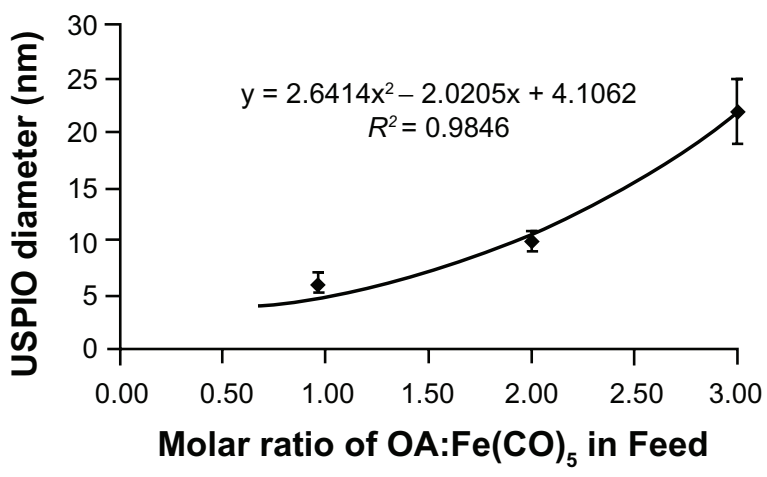

Figure SI Feed ratio of oleic acid surfactant to iron pentacarbonyl precursors and resulting USPIO diameters. A 6 mmol quantity of $\mathrm{Fe}(\mathrm{CO})_{5}$ was introduced into reactors containing $40 \mathrm{~mL}$ octyl ether and varying amounts of oleic acid at $100^{\circ} \mathrm{C}$. USPIO cores were allowed to grow and then oxidize as described in materials and methods, and then imaged by HRTEM. Core diameters were measured via ImageJ software.

Abbreviations: HRTEM, high resolution transmission electron microscope; USPIO, ultrasmall superparamagnetic iron oxides. binding experiments, (S4) nanoparticle cytotoxicity assay, and (S5) control internalization experiments involving MMP-9, MMP-9 inhibitor, and protease-insensitive nanoparticles.

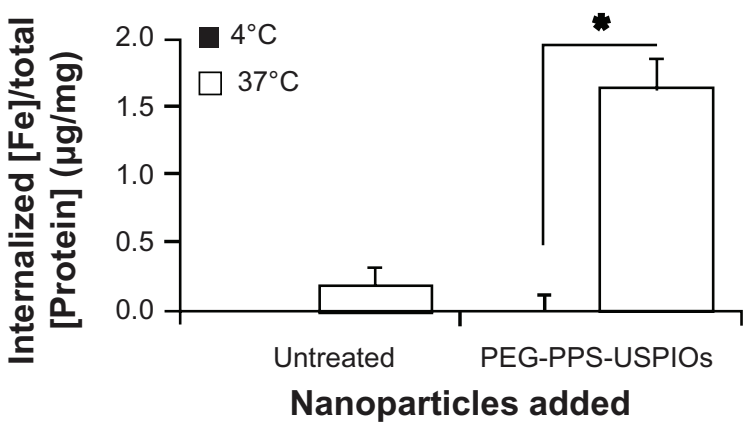

Figure S3 Twenty-four hour uptake of nanoparticles by THP-I macrophages. Cells were treated with $40 \mathrm{~nm}$ PEG-PPS-USPIOs for 24 hours, and then measured for iron content via the phenanthroline assay. Iron content was normalized to cell number indirectly via a protein assay. To confirm that the phenanthroline assay measures internalized nanoparticles and not just nanoparticles that have bound to macrophage receptors, some cells were incubated with nanoparticles at $4^{\circ} \mathrm{C}$. Results showed about ten-fold lower iron content in these samples relative to samples treated at $37^{\circ} \mathrm{C}$, indicating that the protocol successfully lyses cells and enables measurements of internalized iron.

Note: Error bars indicate standard deviation of three independent experiments $(* P<0.01)$.

Abbreviations: PEG, poly(ethylene glycol); PPS, poly(propylene sulfide); USPIO, ultrasmall superparamagnetic iron oxides; THP, human acute monocytic leukemia cell line.

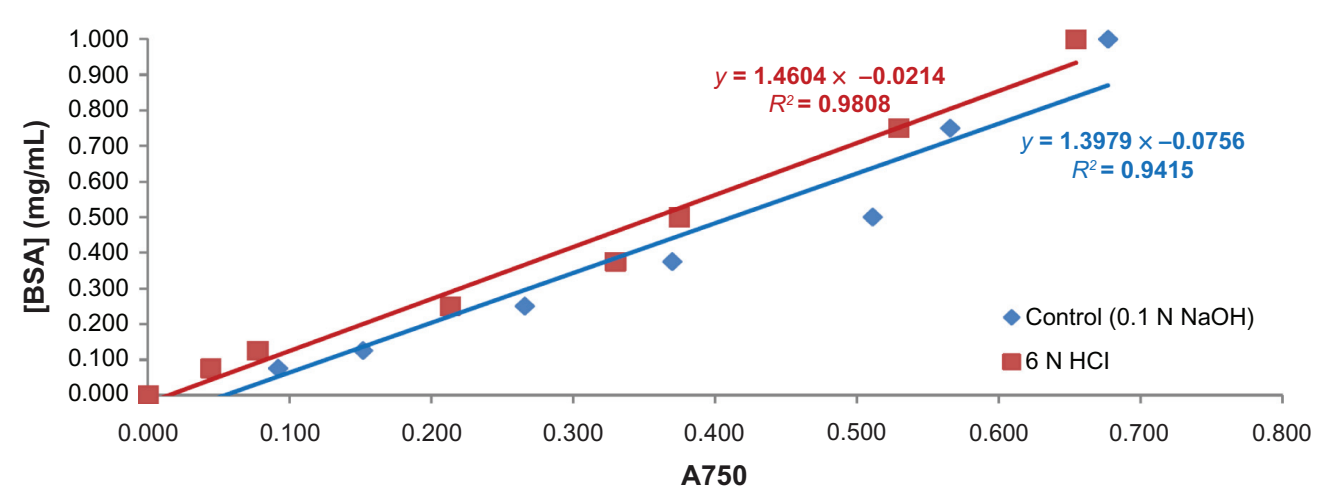

Figure S2 Lowry protein assay standard curves. BSA was dissolved in PBS and treated with either $0.1 \mathrm{~N} \mathrm{NaOH}$ or $6 \mathrm{~N} \mathrm{HCl}$ prior to performance of the Lowry protein assay. While the assay is typically run under alkaline conditions (blue), strong acidic conditions do not significantly affect the sensitivity or reliability of this assay.

Abbreviations: BSA, bovine serum albumin; PBS, phosphate buffered saline. 


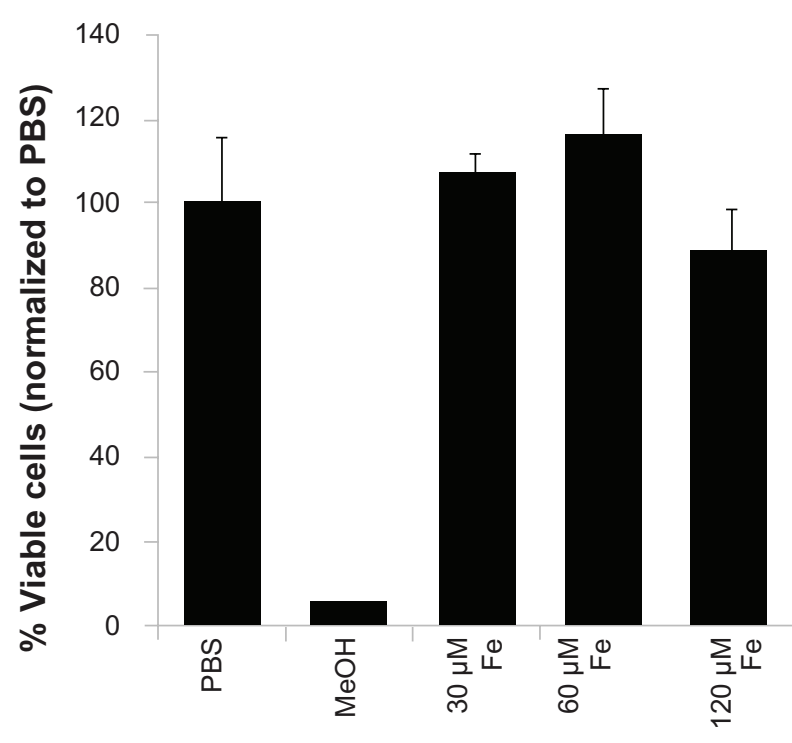

Figure S4 Cell viability measurements on nanoparticle-treated THP-I cells, normalized to untreated cells (media + PBS). Cells were treated with increasing doses of $100 \mathrm{~nm}$ PEG-PPS-USPIOs for 24 hours, prior to removal of unbound nanoparticles and assessment of cell viability via quantification of calcein-AM/ethidium homodimer staining. Dosage on the $\mathrm{x}$-axis represents actual iron concentration within the samples. No statistically significant differences in viability were observed between any of the treatment groups $(n=3)$.

Abbreviations: PBS, phosphate buffered saline; PEG, poly(ethylene glycol); PPS, poly(propylene sulfide); USPIO, ultrasmall superparamagnetic iron oxides; THP, human acute monocytic leukemia cell line.

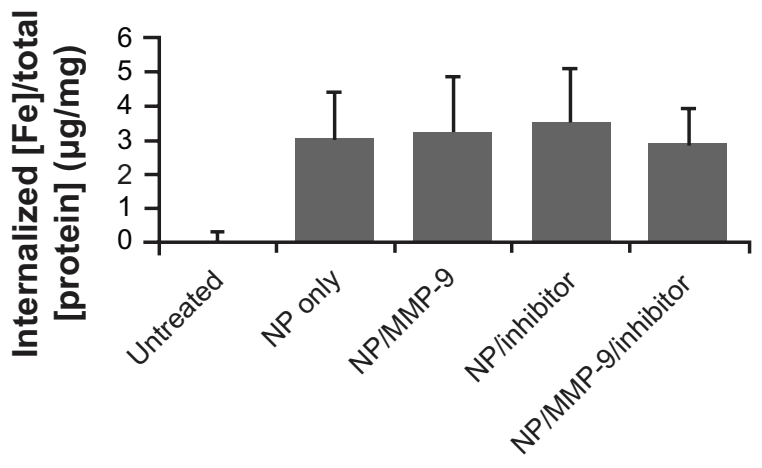

Figure S5 Co-administration of $40 \mathrm{~nm}$ PEG-PPS-USPIOs (do not contain MMP9-cleavable peptide) with MMP-9 does not significantly affect internalization of nanoparticles. THP-I cells were treated with media only (untreated), nanoparticles only, or nanoparticles co-administered with $200 \mathrm{ng} / \mathrm{mL}$ MMP-9 and/or $300 \mathrm{ng} / \mathrm{mL}$ MMP-9 inhibitor. Because these nanoparticles do not contain MMP-9-cleavable elements, their diameter is unaffected by treatment (data not shown). MMP-9 treatment does not change the properties of the THP-I cell membrane in a way that affects their interactions with nanoparticles. Error bars indicate standard deviation for three independent experiments.

Abbreviations: MMP-9, matrix metalloproteinase-9; PEG, poly(ethylene glycol); PPS, poly(propylene sulfide); USPIO, ultrasmall superparamagnetic iron oxides; THP, human acute monocytic leukemia cell line.
International Journal of Nanomedicine

\section{Publish your work in this journal}

The International Journal of Nanomedicine is an international, peerreviewed journal focusing on the application of nanotechnology in diagnostics, therapeutics, and drug delivery systems throughou the biomedical field. This journal is indexed on PubMed Central, MedLine, CAS, SciSearch ${ }^{\circledR}$, Current Contents ${ }^{\circledR} /$ Clinical Medicine,

\section{Dovepress}

Journal Citation Reports/Science Edition, EMBase, Scopus and the Elsevier Bibliographic databases. The manuscript management system is completely online and includes a very quick and fair peer-review system, which is all easy to use. Visit http://www.dovepress.com/ testimonials.php to read real quotes from published authors. 